\title{
Dynamic stability analysis and basic action for struggle with dynamic soil liquefaction
}

\author{
Evgeny Sobolev ${ }^{1, *}$, and Anatoly Buslov ${ }^{2}$ \\ ${ }^{1}$ Moscow State University of Civil Engineering, Yaroslavskoe shosse, 26, Moscow, 129337, Russia \\ ${ }^{2}$ JSC Research Center of Construction, Ryazansky Av., 59, Moscow, 109428, Russia
}

\begin{abstract}
The construction of buildings and structures in seismically hazardous areas is closely connected with the solution of the question of the dynamic stability of the soil base. World experience shows that the most destructive effect of seismic action is dynamic liquefaction. The probability of occurrence and intensity of this process are determined by the geological and hydrogeological structure of the soil massif. Based on the results of special laboratory and field dynamic tests of soils, it is not always possible to completely exclude the possibility of developing this extremely negative process. In this paper, the main stages of the analysis of the dynamic stability of the soil of the foundations of buildings and structures in complex engineering-geological conditions are presented. A brief review of existing domestic and foreign measures for the protection of buildings and structures from the dynamic dilution of soils is given. Information is provided on the applicability and comparative effectiveness of the methods in question.
\end{abstract}

\section{Determination of seismic effect parameters}

The value of the cyclic tangential stress at any point below the horizontal surface of the earth during an earthquake when passing from below the shear wave can be determined using the method proposed by Seed H.B. and Idriss I.M. [1-3]. Assuming that the columnar column with height $\mathrm{h}$ moves horizontally, the maximum shear stress $\tau$ max acting on the foundation of the ground column will be

$$
\tau_{\max }=\frac{a_{\max }}{g} \cdot r_{d} \cdot \gamma \cdot h
$$

where: $a_{\max }$ is the peak value of the horizontal acceleration on the surface of the ground; $g$ acceleration of gravity; $\gamma$ is the specific gravity of the soil; $r_{d}$ is the stress reduction coefficient, taking into account the deformability of the soil column, the value of which is less than one.

\footnotetext{
* Corresponding author: e.s.sobolev@mail.ru
} 
Dividing each part of formula (1) by the effective stress $\sigma_{z}^{\prime}$, we obtain a modified formula that takes into account the distribution of total and effective stresses in the soil column

$$
\frac{\tau_{\max }}{\sigma_{z}^{\prime}}=\frac{a_{\max }}{g} \cdot r_{d} \cdot \frac{\sigma_{z}}{\sigma_{z}^{\prime}}
$$

where: $\sigma_{z}=\gamma h$ - total vertical stress.

Equation (2) is widely used [4-10] to determine the value of the tangential stress that appears in the soil element during the earthquake. The advantage of using Eq. (1) in the analysis of tangential stresses, with seismic action in the horizontal strata of the soil, is a significant amount of accumulated information on horizontal acceleration recorded on the surface of the ground [11-14].

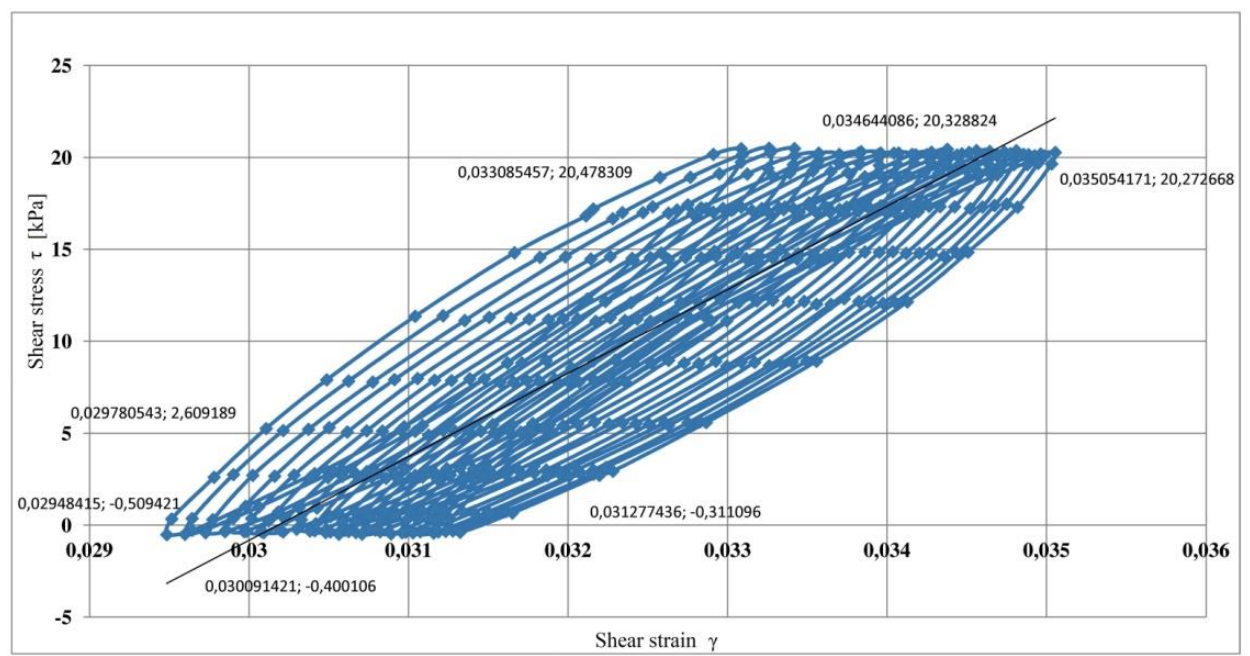

Fig. 1. The results of determining the dynamic strength of clay in evaluating the process of liquefaction caused by seismic action. Dependences of the shear strain of shear on the shear stress for given seismic parameters.

Analysis of the dynamic liquefaction process can be performed by comparing the tangential stress caused by the seismic load and the tangential stress required to initiate the liquefaction of the soil, or the level of shear strain amplitude that is considered unacceptable for design [15-17]. The criterion for determining the dynamic strength [5] is the appearance of a $10 \%$ axial strain in the soil sample, as well as an increase in the pore water pressure to the value of the domestic pressure at the depth of the sample (reduced pore pressure PPR $=1.0$ ). Using the formula (2), it is possible to calculate the cyclic stress that is valid for a given seismic action, and the strength of the soil under dynamic influence can be determined from the results of soil tests in dynamic triaxial compression devices [18-20]. If we express the relative magnitude of the applied stresses through the relative equivalent voltage $\tau_{a v} / \sigma_{z}^{\prime}$, then the corresponding strength must be expressed in terms of the relative equivalent stress $\tau_{a v, l} / \sigma_{z}^{\prime}$. In this case, $\tau_{a v}$ is the average amplitude of the cyclic action, which is 0.65 of the maximum shear stress $\tau$ max. Thus, the potential for liquefaction of the soil layer can be estimated via the safety factor $F_{l}$ : 


$$
F_{l}=\frac{\tau_{\max , l} / \sigma_{z}^{\prime}}{\tau_{\max } / \sigma_{z}^{\prime}}=\frac{\tau_{a v, l} / \sigma_{z}^{\prime}}{\tau_{a v} / \sigma_{z}^{\prime}} .
$$

It is not difficult to note that when the relative maximum or equivalent stresses are used, the safety factor remains unchanged. If the safety factor is less than or equal to one $F_{l} \leq 1$ the liquefaction occurs, otherwise it is absent.

The relative level of tangential stresses $\tau_{a v} / \sigma_{z}^{\prime}$ acting in the ground is often called the reduced cyclic shear stress CSR (cyclic stress ratio), and the value of the cyclic strength is called the reduced cyclic resistance of the $C R R$ (cyclic resistance ratio). Calculationexperimental methods for estimating the potential (dilution potential) are based on a comparison of the values of $C S R$ and $C R R$.

\section{Calculation of dynamic stability}

To determine the dynamic strength of soils [4] under laboratory conditions, tests are performed on triaxial compression devices with dynamic loading [21-23]. The soil sample is compacted by the isotropic pressure $\sigma_{0}^{\prime}$ and an initial static shear stress $\sigma_{s}$ applied to it. Then, a predetermined number of shearing stress cycles are applied to the sample successively, while performing several series of uniform axial loads under undrained conditions with increasing amplitude. The series of loads with increasing amplitude are repeated until the criterion for determining the dynamic strength referred to above is reached. In this case, the relative equivalent stress $\tau_{a v, l} / \sigma_{z}^{\prime}$ is fixed at the moment of achievement of the strength criterion.

\section{Relative levels of shear stresses CSR and CRR}

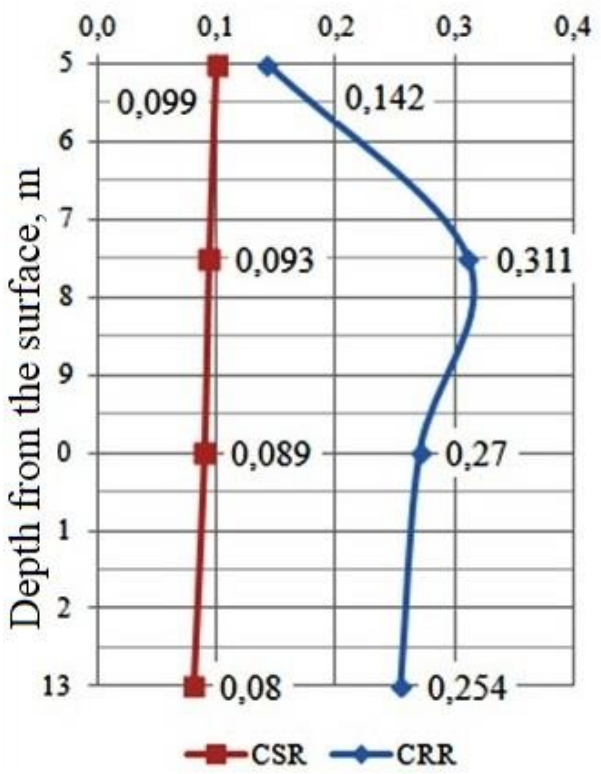

a)

\section{Liquefaction potential $F_{l}$}

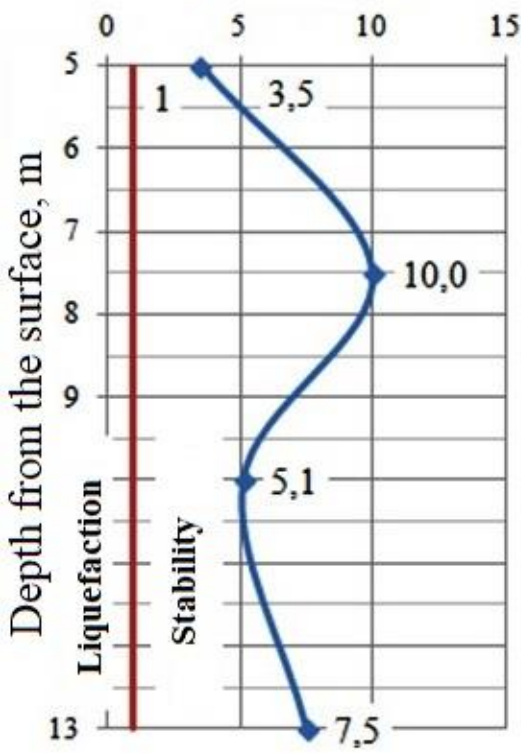

b)

Fig. 2. The results of the determination of the dynamic strength of a dusty clay soil in evaluating the process of liquefaction caused by seismic action. Dependences of the relative stresses acting in the ground $(a)$ and the liquefaction potential $(b)$ on the depth of occurrence of soils in the massif. 
By comparing the obtained values of the dynamic strength with the values of the predicted tangential stresses under the predicted seismic action, it is possible to construct a plot of the liquefaction potential along the depth of the considered soil mass (Figure 2b). Since it is generally accepted [1-2] that the possibility of dynamic liquefaction decreases with depth, it is necessary to subject water-saturated soil samples taken from depths to 20-25 meters. The frequency and number of loading cycles in the tests depends on the parameters of the predicted seismic action.

\section{Measures to prevent liquefaction}

The possibility of occurrence of dangerous for the stability and strength of the constructions of the zones of liquefaction of disconnected soils makes it necessary to apply a number of measures to combat these phenomena [24-25].

All the measures used for this purpose in engineering practice according to the nature of their action can be divided into two types [25-29]:

a) preventing the possibility of liquefaction;

b) reducing the harmful effects of liquefaction.

The second type of measures, unlike the first one, does not influence the conditions that determine the possibility of destruction of the structure of sandy ground and the appearance of liquefaction phenomena, but only reduces the residence time of sand in the liquefied state and prevents or reduces the displacement of liquefied sand masses and structures erected on them.

Measures to prevent the possibility of liquefaction are very diverse and proceeding from the conditions that determine the appearance of liquefaction phenomena, in turn, can be divided into the groups shown in Figure 3.

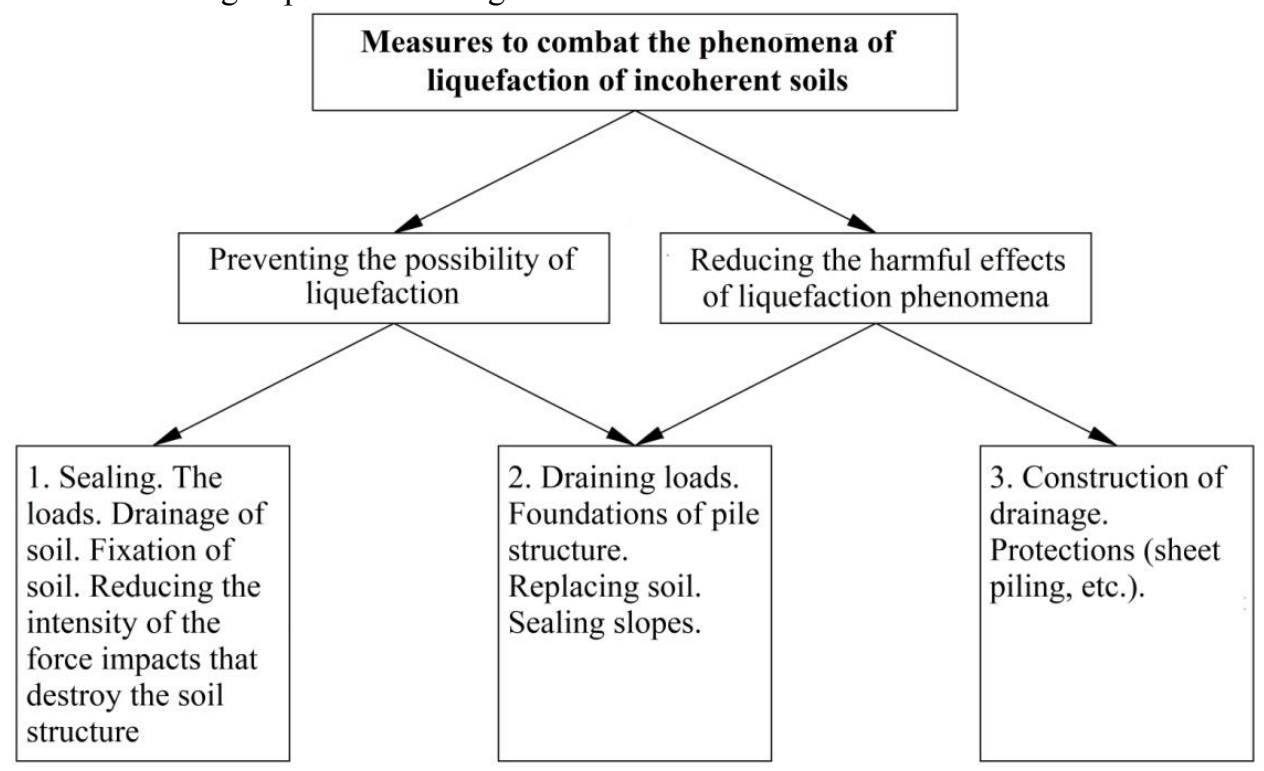

Fig. 3. Classification of measures to combat the phenomena of liquefaction of incoherent soils [24].

One of the important conditions affecting the choice of measures are permissible deformations and displacements of structures. In a number of cases, especially in earthworks, it may be more rational to allow the possibility of small deformations of slopes and even local soil seams with the greatest in intensity but least frequent repetitive dynamic 
impacts (for example, with the maximum possible in this region but very rare seismic impact). Possible costs for repairing the structure may be several orders of magnitude less than the cost of special measures for the full prevention of liquefaction performed during the construction period.

\section{Conclusion}

Main conclusions:

1. Long-term forecasting of the stress-strain state of soil massifs in complex engineering-geological conditions and taking into account the increased responsibility of buildings and structures is impossible without taking into account the behavior of soils under seismic action.

2. To assess the potential for liquefaction of soils under seismic influences, it is necessary to estimate the level of predicted impact and strength of soils under dynamic impact. Having determined the relative tangential stresses acting in the soil massif, it is possible to correlate them with the dynamic strength obtained from the results of special laboratory dynamic tests of soils.

3. The method allows estimating the liquefaction potential in the depth of the soil massif and determining the thickness of the soils, which, under seismic action, can be subject to dynamic liquefaction.

4. All measures used in engineering practice by the nature of their action can be divided into two types: preventing the possibility of liquefaction and reducing the harmful effects of liquefaction.

5. The choice of measures to combat dynamic dilution depends on the engineering and geological conditions of the construction site, the structural and technological features of the structure, as well as the capabilities of the construction organization.

All tests were carried out using research equipment of The Head Regional Shared Research Facilities of the Moscow State University of Civil Engineering (RFMEFI59317X0006).

\section{References}

1. Seed H.B., Idriss I.M., J. of Soil Mechanics and Foundation Engeneering, ASCE, 97, 1249-1273 (1971)

2. Seed H.B., Idriss I.M., J. of Soil Mechanics and Foundation Engeneering, ASCE, 97, 1249-1273 (1971)

3. Seed H.B. J. of Soil Mechanics and Foundation Engeneering, ASCE, 105, 201-255 (1996)

4. K. Ishihara The behavior of soils during earthquakes: Trans. from English. Ed. A.B. Fadeev, M.B. Lisyuka. 384 (St. Petersburg, NGO GeoreconstructionFundamentproject, 2006)

5. E.A. Voznesenskij, V.V. Funikova, E.S. Kushnareva, V.G. Kovalenko, Exploration and conservation of mineral resources, 12, 61-65 (2005)

6. E.A. Voznesenskij, Situation and standardization. Engineering survey J., 5, 20-26 (2013)

7. E.A. Voznesenskij, M.S. Nikitin, E.A. Sencova, Geotechnics J., 2, 4-17 (2016)

8. I.T. Mirsajapov, I.V. Koroleva, G.Z. Zaripova, Soil Mechanics and Foundation Engineering in Geotechnical Engineering: materials of the international scientific and 
technical conference, Novocherkassk, 13-15 May 2015 South-Russian State Technical University (NPI) to them. MI Platov. Novocherkassk, YURGPU (NPI), 31-37 (2015)

9. I.T. Mirsajapov, I.V. Koroleva, Grounds, foundations and soil mechanics J., 1, 5-10 (2016)

10. I.T. Mirsajapov, I.I. Aljushev, Proceedings of the Kazan State Architectural University J., 3 (37), 173-178 (2016)

11. I.T. Mirsayapov, I.V. Koroleva, Proceedings of the XVI European conference on soil mechanics and geotechnical engineering, ECSMGE, 3249-3254 (2015)

12. J. Chu, W.K. Leong, W.L. Luke, D. Wanatowski, Journal of Geotechnical and Geoenvironmental Engineering, ASCE, 138, 207-216 (2012)

13. T. Iwasaki, K. Tokida, F. Tatsuoka, S. Watanabe, S. Yasuda, H. Sato, Proc. 3rd Int. Conf. On Microzonation. Seattle, 3, 1319-1330 (1982)

14. J.A. Yamamuro, P.V. Lade, Canadian Geotechnical J., 34, 6, 905-917 (1997)

15. H.F. Zhao, L.M. Zhang, Journal of Geotechnical and Geoenvironmental Engineering, ASCE, 140, 25-35 (2014)

16. L.R. Stavnicer, Seismic stability of the foundations, 448 (Moscow, Association building universities, 2010)

17. L.R. Stavnicer, Collection of scientific works NIIOSP them. N.M. Gersevanov. Moscow, Research, Design and Technology Institute of Foundations and Underground Structures them. N.M. Gersevanov - Institute JSC SEC Construction, 352-357 (2011)

18. L.R. Stavnicer, Security buildings J., 2, 56-58 (2012)

19. Z. Ter-Martirosyan, A. Ter-Martirosyan, E. Sobolev Procedia Engineering. XXV Polish - Russian - Slovak Seminar Theoretical Foundation of Civil Engineering, 153, 747-753 (2016)

20. Z.G. Ter-Martirosyan, A.Z. Ter-Martirosyan, E.S. Sobolev, Advanced Materials Research J., 1073-1076, 1673-1679 (2014)

21. Z.G. Ter-Martirosyan, E.S. Sobolev, A.Z. Ter-Martirosyan, Proceedings of the XVI European conference on soil mechanics and geotechnical engineering, ECSMGE, 3365-3369 (2015)

22. E.S. Sobolev, A.Z. Ter-Martirosjan, Building - the formation of living environment, a collection of materials XIX International interuniversity scientific-practical conference of students, undergraduates, graduate students and young scientists. National Research Moscow State University of Civil Enginering, 1087-1090 (2016)

23. A.Z. Ter-Martirsjan, A.Ju. Mirnyj, E.S. Sobolev, Geotechnics J., 1, 66-72 (2016)

24. Z.G. Ter-Martirsjan, A.Z. Ter-Martirosjan, E.S. Sobolev, Engineering survey J., 5-6, 24-28 (2014)

25. P.L. Ivanov, Liquefaction of sandy soils, 260 (Leningrad, Gosjenergoizdat, 1962)

26. P.L. Ivanov, Liquefaction and compacting non-cohesive soils under dynamic loading, 52, (Leningrad, LPI im. M.I. Kalinina, 1978)

27. T.T. Abramova, Geotechnics J., 4, 36-49 (2016)

28. T.T. Abramova, E.A. Voznesenskij, Geotechnics J., 4, 6-25 (2015)

29. V.A. Il'ichev, Grounds, foundations and soil mechanics J., 5, 15-18 (1981) 